\title{
Research on the Practical Path of "Internet + Social Work" in Spiritual Comfort of Lonely Old People
}

\author{
YangQian ${ }^{1, a^{*}}$ WangZhen ${ }^{2, b}$
}

\begin{abstract}
${ }^{1}$ Changchun University of Science and Technology,School of law, the department of sociology, Changchun,JiLin,China ${ }^{2}$ Changchun University of Science and Technology,School of law, the department of sociology, Changchun,JiLin,China a52362326@qq.com, ${ }^{b} 1428493028 @ q q . c o m$
\end{abstract}

\begin{abstract}
The increasing number of the elderly population has made the issue of old age a hot spot of social concern. The issues of old age care, employment, daily care and survival are frequently discussed, but the spiritual aspects are often neglected by people, however, due to their weak position, the problem of material security for the lonely old people is to be solved. Mental Health Service is a higher level demand for them, but it is the key factor that affects the happiness of the lonely old people. Based on the advantages of the times shown by the combination of "Internet + " and various traditional industries, this paper explores the social background of the rise of "Internet + social work" service mode, to understand the lack of spiritual comfort services for the lonely elderly and their demand, and to summarize the advantages of "internet + social work" in the spiritual comfort of the lonely elderly, to explore the "Internet + social work" in the spirit of lonely elderly relief in the practice of the path.
\end{abstract}

Keywords: elderly person of no family, spiritual comfort, the internet

\section{“互联网+社会工作”在孤寡老人精神慰藉中的实践路径 研究}

${\text { 杨茜 }{ }^{1, \text { a* }} \text { 王真 }}^{2, \mathrm{~b}}$

${ }^{1}$ 长春理工大学法学院社会学系, 长春, 吉林, 中国

2 长春理工大学法学院社会学系, 长春, 吉林, 中国

a52362326@qq.com, ${ }^{b} 1428493028 @ q q . c o m$

\section{中文摘要}

老年人口的不断增多使老年问题成为社会关注热点, 老年人的养老、就业、日常照护、生存等问题被 频繁讨论, 但是精神层面的问题往往受到人们的忽视, 而孤寡老人由于其弱势地位, 丞待解决的是他 们的物质保障问题, 精神健康服务对他们来说属于更高层次的需求, 但却是影响孤寡老人幸福感的关 键因素。本文立足于 “互联网+” 与各种传统行业结合所展现的时代优势, 通过探求 “互联网+社会工 作” 服务方式兴起的社会背景, 了解孤寡老人精神慰藉服务的贯乏及需求表现, 总结 “互联网+社会工 作” 在孤寡老人精神慰藉中的优势，以探讨 “互联网+社会工作” 在孤寡老人精神慰藉中的实践路径。 关键词孤寡老人，精神慰藉，互联网

\section{1. 前言}

改革开放以来，我国经济社会飞速发展，相应的人 口结构也呈现出巨大的调整与转变, 我国已在上世纪末 进入老龄化社会, 老年人口比例逐渐提高, 实现积极老
龄化成为受到中央和各级政府重点关注的民生问题。 由于各种因素的影响, 孤寡老人不断增多, 在某种程 度上成为社会发展的 “代价”，这一部分人群的队伍日 益壮大, 他们无配偶、无子女、丧失劳动能力, 属于 老年人中的 “三无人员”，较之普通老人呈现出更为频 繁的脆弱性与依赖性, 在身体健康、日常照料、精神 


\section{3.孤寡老人精神慰藉服务的匮乏及需求表现}

到人们的忽视, 且精神慰藉的实现至少需要两个主体参 与完成, 孤塞老人在很大程度上更难通过非正式支持满 足这类需求。基于此种情况, 如何将社会工作与时代发 展相结合, 在孤寡老人心理和精神健康层面提供高效的 社会工作服务显得无为重要, 因此本研究的目的在于探 讨 “互联网+社会工作” 在孤寡老人精神慰藉中的适用性, 以及如何利用互联网为孤㘯老人提供有效的社会服务。

\section{2. “互联网+社会工作” 创新服务方式兴起的社 会背景}

“互联网+” 是国家、政府近几年的重要议题, 同时 国家也从政策、法规等层面大力引导社会工作发展, “互 联网+社会工作” 是社会工作行业的发展大势, 通过对文 献的阅读与梳理, 我们认为所谓 “互联网+社会工作” 就 是在社会工作服务环节中将互联网作为服务的工具和媒 介, 利用互联网的先进技术成果, 一方面超越时间和空 间的限制, 为社会工作的实施和推行提供一种简单快捷 的方式, 另一方面提高社会工作者的服务效率, 为服务 对象提供更高效、便捷的服务, 为传统的社会工作实践 插上互联网的翅膀, 利用互联网的大众化特点将社会工 作带入到人们的日常生活中, 以促进社会工作的普及 ${ }^{[1]}$ 。

在过去几年中, “互联网+” 与教育、医疗、餐饮等 行业的结合呈现出更加便捷、高效的服务状态, 使各类 传统服务行业在新的时代背景下找到更符合社会发展的 运转模式, 迸发出新的生机, 社会工作作为专业助人的 职业也应积极顺应时代发展, 创新服务方式, 扩大服务 范围, “互联网+” 与社会工作的结合是时代的必然趋势。 信息时代的到来使互联网深深的植根于现代人的日常生 活, 而社会工作就是解决社会中的人、团体或组织所遇 到的问题, 其在信息时代下的运营与发展必然离不开对 互联网的应用, “互联网+” 与社会工作的结合是时代的 发展要求。2015 年 5 月 6 日, 民政部老年人福利处副 处长孙文灿在中国国际养老服务业博览会上发表题为 《“互联网+” 养老, 未来空间无限》的演讲, 最早提出 了 “互联网+” 养老概念。2016 年发布的《国家十三五 规划》和 2017 年发布的《国务院关于积极推进 “互联 网+” 行动的指导意见》中明确提出了依托现有互联网资 源和社会力量, 搭建公共信息平台和养老信息服务网络 平台, 将智慧养老理念放在政策层面, 促进社会工作与 互联网的结合, 2018 年 9 月 11 日, 民政部印发了《“互 联网+社会组织” 行动方案 (2018-2020 年)》, 着力在未 来三年将《“互联网+民政服务” 行动计划》的相关任务 部署贯彻落实到位, 《方案》致力于推动 “互联网+” 与 社会工作、社会组织等的融合健康发展, 依托互联网打 造社会工作服务对象与服务提供者之间 “零距离、多渠 道、精准化” 的供需对接机制、服务品质评价模式, 推 动社会工作大数据的分析应用等 ${ }^{[2]}$, “互联网 + ” 与社会工 作的结合是政府为社会工作的健康发展所做的重要战略 部署。
孤寡老人是指无配偶、无子女、没人照顾、年龄 超过 60 周岁且丧失劳动能力的人。这一部分老人处于 社会生活的弱势地位, 关于其所面临的物质生活困境 已被广泛研究, 精神需求的满足对他们来说更为迫切, 孤葟老人所面临的精神困境主要有: 孤葟老人由于缺 乏亲情支持, 家庭结构异常, 长期独自居住的生活状 态使得他们缺乏心理纾解渠道, 孤独感与消极情绪占 据主导地位; 另一方面孤寡老人收入普遍较低, 生理 条件不断退化, 除去要面临的物质生活压力, 疾病所 带来的经济与心理压力更成为孤寡老人心头的 “愁”; 孤葟老人的社会支持网络较为薄弱, 自卑与消极的心 理状态又阻碍了他们与外界建立良好的沟通, 两者相 互作用在孤葟老人身上成为恶性循环, 长此以往孤葟 老人容易自我封闭, 形成孤僻人格, 影响心理健康, 成为社会发展的“负担”; 孤塞老人大多数都挣扎于“温 饱线”上, 对他们来说拥有富足的物质生活已是难题, 加之老年市场发育缓慢, 精神服务是他们更短缺却更 难得到的, 求助无门使孤寡老人所面临的困境不能被 打破。

精神慰藉就是针对于老年人面临的精神困境所产 生的服务, 目前还没有确切的关于精神慰藉的含义, 通过对相关文献的梳理, 我们认为精神慰藉是指: 以 发挥服务对象自身能动性为前提, 为他们提供精神层 面的支持与帮助, 促成他们的身心协调发展, 通过改 善他们的心理状态, 不断满足他们对于他人关怀、娱 乐活动和实现人生价值等精神层面需求的活动 ${ }^{[3]}$ 。孤 萓老人相较于普通老人更渴望得到精神慰藉, 过往调 查中显示, 孤葟老人对于精神慰藉方面的需求主要表 现为: 对稳定、和谐的邻里关系的需要、希望得到陪 伴及社区的关怀、心理咨询服务的需求等, 这些需求 从侧面反映出服务市场的滞后与不健全。

随着经济水平的提高、国家老年社会保障制度的 不断完善以及社会助老组织队伍的壮大, 老年人的物 质生活、日常照料等方面的问题得到了社会大众的关 注, 并在很大程度上得到了解决, 随之而来的是老年 人需求方向的转变, 开始更多表现出精神慰藉和心理 层面的缺失, 相比于普通老人, 孤寡老人在获得精神 及心理方面支持的渠道闭塞，而此时服务市场的关注 焦点不能及时从物质生活转移到精神需求, 表现出严 重的滞后性; 另一方面, 精神慰藉是继老年人经济、 生活需求之后的一种高层次需求, 而国家经济发展的 不平衡使精神慰藉服务不能成为当前为老服务的主要 目标, 难以在大范围内拓展, 因此关于老年人精神健 康的服务往往被忽视, 而关于孤寡老人的社会工作服 务也多集中于为孤寡老人链接资源、提供物质帮助上, 不能触及更深层次的需求; 其次, 我国社区建设较为 落后, 功能尚未完善, 社会组织和社区在提供服务时 由于缺少量化的标准和专业手段, 现有的针对孤寡老 人进行精神慰藉的服务也表现出低效率、专业性不足、 无法满足实际需要的问题, 欠缺真正有效的针对孤葟 老人的精神慰藉服务。现今, 社会上对于老年人精神 
慰藉的呼吁越来越多, 我们应该注意到孤寡老人在获得 精神慰藉服务层面所处的弱势地位, 如何更好的为孤寊 老人提供精神慰藉服务是需要我们去思考的问题 。

\section{4. “互联网+社会工作” 在孤塞老人精神慰藉服 务中的优势与挑战}

“互联网+社会工作” 是国家、政府以及时代的倡导 与必然趋势, 两者的结合将为孤寡老人的精神慰藉提供 以下便利: 其一, “互联网+社会工作” 在孤塞老人精神 慰藉的应用可以使社会工作服务借助互联网的间接性突 破时空限制, 同时其强互动性可以增强孤寡老人与社会 工作者之间的联系, 提升服务效率, 从而弥补单纯线下 服务对孤寡老人支持强度弱的缺点, 真正实现对孤塞老 人的陪伴与精神慰藉。其二, 在为孤塞老人提供服务时 可借助其身边的有效资源在互联网的作用下形成以孤葟 老人为中心的 “物联网”, 拓展孤寡老人的社会支持网络; 同时可通过互联网实现资源的链接与调配，优化服务资 源配置方式, 实现资源的合理调配, 互联网的使用不仅 会加强工作者与孤寡老人之间的联系, 同时也会加强各 服务参与者包括政府部门及社会组织之间的联系, 实现 信息的共享, 聚合力以解孤葟老人之难题, 最终达到社 工服务的高效运作。其三, 社会工作者通过互联网为孤 寡老人提供精神慰藉服务也可以拓展孤塞老人的知识技 能, 在接受社工服务的同时丰富老年生活, 开辟新的获 取精神支持的渠道一互联网; 其四, “互联网+社会工作” 的服务方式可以实现互联网基础上社工与孤寡老人的高 效沟通, 社工通过互联网可以更准确的感知孤寡老人的 情绪、情感的变化, 从而选择更有效的服务方式以提升 服务效果, 另一方面孤塞老人也可以通过网络平台对社 会工作者的服务过程进行监管, 以使服务更加的 “得人 心”。最后互联网基础上大数据的融合运用, 通过智能化 的管理与分析系统数据的参考, 比单纯凭经验的精神慰 藉工作更有针对性, 准确性更高 ${ }^{[4]}$, 而且通过互联网的分 析能够为孤寡老人精神慰藉的方法选择提供科学依据, 更好的把握不同情况下孤寡老人的真实精神需求。

鉴于目前互联网在社会工作中的运用只是停留在初 级阶段, 社会工作对互联网的开发应用比较单一, 对互 联网的作用没有引起足够的重视, 在孤寊老人精神慰藉 社会工作中运用互联网也可能会面临挑战, 如由于互联 网的虚拟性与间接性可能会造成社工与孤塞老人之间的 隔阂, 影响服务效果; 我国互联网的管理立法工作滞后, 无法为网络社会工作的开展提供保障; 互联网是一个 “相 对” 安全的社区, 孤塞老人的个人隐私信息存在泄漏风 险等, 但总体来说机遇大于挑战, 互联网在孤寡老人精 神慰藉领域是有自己的独特优势存在的, 其所面临的挑 战也是可以通过优化服务系统进行改善的, 因此, “互联 网+社会工作” 在孤寡老人精神慰藉的应用具有较强的适 用性。

\section{5. “互联网+社会工作” 在孤寡老人精神慰藉 中的实践路径}

目前我们的社会工作实践还处于 “互联网+社会工 作” 服务方式的初级阶段, 部分社会工作者和社会工 作机构已经有意无意地利用互联网达至社会工作的助 人目标, 但并非在整个助人过程中都依靠互联网或在 网络空间内进行, 互联网只是其实现助人目标的阶段 式辅助性工具 ${ }^{[5]}$ 。虽然随着科技的发展, 在不久的未 来 “无接触社会工作服务” 会成为现实, 但目前我们 所讨论的 “互联网+社会工作” 的实践路径立足于当前 社会工作实践现状, 因此要讨论的是如何实现线上线 下服务相结合提升社会工作服务效果的实践路径。

大体来说, 社会工作为孤寡老人提供精神慰藉服 务主要以个案和小组两种工作方式来进行, 在具体工 作环节中可将 “互联网+社会工作” 的实践划分为: 以 互联网为平台的实践、以互联网为工具的实践和以互 联网作为活动场域的实践。首先, 以互联网为平台的 实践主要应用于个案和小组工作的活动初期与建立关 系阶段, 其一可做宣传平台, 这一时期社会工作者与 孤寡老人通过互联网相互了解, 社会工作者可借助网 站、微信公众号、官方微博或社区内线上服务平台进 行活动信息的发布, 孤寡老人通过这些渠道获取服务 信息, 较之传统的宣传方式更为灵活, 对孤寡老人来 说这种宣传方式可在宣传范围与效果上收获成效。其 二可做沟通平台, 利用互联网的强互动性可以增强与 孤寡老人的联系, 也可以避免由于服务开始前期孤塞 老人不能对社会工作者卸下 “心防” 而导致的服务终 止; 以互联网为沟通媒介大大提高了社会工作的服务 效率, 突破时空限制, 便捷了社会工作的服务过程; 互联网上电子信息的传输使社工能更准确的感知孤寡 老人的精神状态与情绪变化, 更能体现社会工作对孤 寡老人的精神慰藉。

以互联网为工具的实践活动主要应用于服务活动 的实施及收尾期, 以三种作用来表现, 其一, 作为拓 展孤塞老人支持网络的工具, 互联网如今已经发展成 为一个全新的 “虚拟社会”, 我们可以通过互联网连接 到现实社会中的诸多 “资源拥有者”, 如可以针对孤寡 老人所表现出来的心理问题为其寻找专业的心理咨询, 对其所面对的生活困境链接到社会专业组织来解决等, 这些资源的高效合理利用将拓展孤寡老人的正式支持 网络; 互联网也为我们寻找孤塞老人的同质群体提供 了便捷的渠道, 通过即时通讯软件为同质孤葟老人建 立 $\mathrm{QQ}$ 群组或微信群组, 从而形成社工与孤臭老人及孤 葟老人之间的互助网络或网络社区, 这有助于孤葟老 人建立自身的社会支持网络、形成支持性小组, 在此 过程中社工扮演组织者和引导者的角色; 同时互联网 也可以加强孤塞老人与周围环境之间的关系, 可利用 互联网的互通性为孤寡老人建立与周边资源的联系， 形成关于孤塞老人自身的 “物联网”, 加强对于孤塞老 人的非正式支持。其二, 可作丰富孤葟老人精神生活 的工具, 信息社会下互联网已成为可满足人们精神需 求等众多需求的重要工具, 通过互联网对孤寡老人进 
Connotation and Development Path J. Journal of Hotan Teachers College, 2016,3501:110-114.
行精神慰藉可以使孤寡老人获取关于互联网的知识技能, 这也为他们开辟了满足精神需求的新渠道。其三, 可作 社会工作监督、评估的工具, 与孤寡老人的线上交流可 作为服务评估与改进的依据, 孤寡老人也可通过互联网 实施对社会工作服务的监督, 以更好地改进服务、满足 自身需求。

以互联网作为活动场域的实践活动更多存在于小组 工作为孤寡老人设计的线上服务活动中, 社会工作者可 根据孤寡老人群体的实质需求设计具备线上实施条件的 小组活动, 在线上小组活动中孤寡老人群体内部可通过 信息活动、视频互动等方式开展活动, 这种形式较之传 统小组活动具有更高的灵活性与操作性, 也能更顺利的 实现对孤寡老人的精神慰藉。

\section{6. 结论}

以上所讨论的实践活动是 “互联网+社会工作” 在孤 葟老人精神慰藉服务活动中的应用策略, 但基于目前的 现实情况, 社会工作实践活动仍然不能脱离传统服务模 式, 因此在具体的服务运作过程中应依据孤寡老人的现 实情况灵活运用线上线下服务方式, 合理设置服务活动, 以在传统精神慰藉服务的基础上提升服务效率，充分发 挥 “互联网+社会工作” 在孤寡老人精神慰藉中拥有的独 特优势, 真正实现对孤寡老人的精神慰藉。

\section{项目基金}

本文为吉林省教育厅 “十三五” 社会科学研究《社会工 作参与吉林省农村精准扶贫的路径与对策研究》

(JJKH20190609SK)、《吉林省城市贫困群体可持续生计 问题研究（JJKH20190608SK）的阶段性成果之一。

\section{REFERENCES}

[1] Chen XiaoXing. The application of Internet in Social Work Service J. Social Work and management, 2018,1803:43-50.

[2] "Internet + Social Organizations(Social Work, Volunteering)" Action Plan(2018-2020)[ J] .. China Civil Affairs, 2018(18): 43-46.

[3] Li Jing. A case study on the spiritual relief of the low-income and widowed Elderly D. Changchun University of Science and Technology, 2019.

[4] Zhang Jun, Zheng Nanan. "Internet + social work" intervenes the path innovation of intelligent poverty alleviation — A field study based on the $\mathrm{R}$ institution in northern Anhui. Journal of the Anhui Agricultural University, 2019,2801:94-100.

[5] Zhao Wanlin. Network Social Work: concept, 